\title{
HIV, cyclophilins and nuclear entry: going under the radar
}

\author{
Greg Towers \\ From Frontiers of Retrovirology 2011 \\ Amsterdam, The Netherlands. 3-5 October 2011
}

Lentiviruses such as HIV-1 traverse nuclear pore complexes (NPC) and infect terminally differentiated nondividing cells, but how they do this is unclear. Here we define a pathway involving direct interaction between HIV-1 capsid (CA) and cytoplasmicCyclophilinA (CypA), and the nuclear pore cyclophilin Nup358/ RanBP2. We show that these interactionsare essential for integration targeting and replication in primary human macrophages. In contrast to CypA Nup358 cyclophilin is insensitive to inhibition with cyclosporine. Inhibition of CypAusing cyclosporine or depletion of CypA levels by RNAi forces HIV-1 to enter the nucleus independently of Nup358 and the nuclear basket protein Nup153, suggesting that CypA regulates the choice of the nuclear import machinery that is engaged by the virus. Substitutions in capsid modulating CypA/Nup358 interactions switch integration into higher or lower gene density regions. HIV-1 cyclophilin-binding mutants CA G89V, P90A, or chimaeric HIV-1 containing SIVmac $\mathrm{CA}$ integrate in genomic areas of high gene density and activity, phenocopying integration of wild type virus in the presence of cyclosporine. In contrast, HIV-1 CA mutants that neither use Nup358 nor transportin 3 (CA N74D, N57A) integrate in genomic areas of low gene density and activity. Importantly, both groups of CA mutants are impaired in replication in HelLa cells and human monocyte derived macrophages. Our findings illustrate how HIV-1 engagescyclophilins to select a nuclear entry pathway required for integration into preferred genomic loci important for optimal proviral gene expression and replication and provide insight into lentiviral conservation of cyclophilin interactions.

Published: 3 October 2011

doi:10.1186/1742-4690-8-S2-07

Cite this article as: Towers: HIV, cyclophilins and nuclear entry: going under the radar. Retrovirology 2011 8(Suppl 2):07.

Submit your next manuscript to BioMed Central and take full advantage of:

- Convenient online submission

- Thorough peer review

- No space constraints or color figure charges

- Immediate publication on acceptance

- Inclusion in PubMed, CAS, Scopus and Google Scholar

- Research which is freely available for redistribution 